\title{
Activation of the Mammalian Target of Rapamycin (mTOR) Is Essential for Oligodendrocyte Differentiation
}

\author{
William A. Tyler, ${ }^{1}$ Nitish Gangoli, ${ }^{1}$ Pradeepa Gokina, ${ }^{2}$ Haesun A. Kim,,${ }^{2}$ Matthew Covey, ${ }^{1}$ Steven W. Levison, ${ }^{1}$ \\ and Teresa L. Wood ${ }^{1}$ \\ ${ }^{1}$ Department of Neurology \& Neuroscience, New Jersey Medical School, University of Medicine and Dentistry of New Jersey, Newark, New Jersey 07101- \\ 1709, and ${ }^{2}$ Department of Biological Sciences, Rutgers University, Newark, New Jersey 07102
}

\begin{abstract}
Although both extrinsic and intrinsic factors have been identified that orchestrate the differentiation and maturation of oligodendrocytes, less is known about the intracellular signaling pathways that control the overall commitment to differentiate. Here, we provide evidence that activation of the mammalian target of rapamycin (mTOR) is essential for oligodendrocyte differentiation. Specifically, mTOR regulates oligodendrocyte differentiation at the late progenitor to immature oligodendrocyte transition as assessed by the expression of stage specific antigens and myelin proteins including MBP and PLP. Furthermore, phosphorylation of mTOR on Ser 2448 correlates with myelination in the subcortical white matter of the developing brain. We demonstrate that mTOR exerts its effects on oligodendrocyte differentiation through two distinct signaling complexes, mTORC1 and mTORC2, defined by the presence of the adaptor proteins raptor and rictor, respectively. Disrupting mTOR complex formation via siRNA mediated knockdown of raptor or rictor significantly reduced myelin protein expression in vitro. However, mTORC2 alone controlled myelin gene expression at the mRNA level, whereas $\mathrm{mTORC1}$ influenced MBP expression via an alternative mechanism. In addition, investigation of mTORC1 and mTORC2 targets revealed differential phosphorylation during oligodendrocyte differentiation. In OPC-DRG cocultures, inhibiting mTOR potently abrogated oligodendrocyte differentiation and reduced numbers of myelin segments. These data support the hypothesis that mTOR regulates commitment to oligodendrocyte differentiation before myelination.
\end{abstract}

\section{Introduction}

The differentiation of oligodendrocyte progenitor cells (OPCs) into mature oligodendrocytes is a complex process that requires cell cycle exit and the coordinate expression of genes required for maturation and myelination. Whereas several transcription factors have been identified that are essential for OPC differentiation, intermediate signaling pathways that link external regulators with the transcription factors that promote the transition from a progenitor to a myelinating oligodendrocyte remain unclear.

Several studies suggest that the PI3K/Akt pathway, which is activated by growth factors and extracellular matrix (ECM) molecules, promotes oligodendrocyte differentiation and myelination. For example, deletion of the endopeptidase BACE1 in mice causes hypomyelination because of the improper cleavage of neuregulin, which in turn leads to decreased phosphorylation of Akt (Hu et al., 2006). Insulin-like growth factor (IGF)-I, which pro-

Received Jan. 15, 2009; revised March 22, 2009; accepted March 27, 2009.

This study was supported by National Institute of Neurological Disorders and Stroke Grants NS37560 (T.L.W.) and NS056135 (H.A.K.), National Institute of Mental Health Grant MH59950 (S.W.L.), and by the University of Medicine and Dentistry of New Jersey NeuroProteomics Core Grant P30NS046593 from the National Institute of Neurological Disorders and Stroke. We would like to thank S. Priyadarshini and W. Macklin for helpful discussions and comments on this manuscript.

Correspondence should be addressed to Teresa L. Wood, Department of Neurology \& Neuroscience, University Hospital Cancer Center H1200, New Jersey Medical School/ University of Medicine and Dentistry of New Jersey, 205 South Orange Avenue, Newark, NJ 07101-1709. E-mail: woodte@umdnj.edu.

DOI:10.1523/JNEUROSCI.0234-09.2009

Copyright $\odot 2009$ Society for Neuroscience $\quad 0270-6474 / 09 / 296367-12 \$ 15.00 / 0$ motes sustained Akt phosphorylation in oligodendroglia (Ness and Wood, 2002), also has an essential role in CNS myelination in vivo. IGF-I overexpression in mice causes CNS hypermyelination (Carson et al., 1993). Conversely, genetic deletion of IGF-I systemically (Beck et al., 1995; Ye et al., 2002) or of the IGF-IR in OPCs (Zeger et al., 2007) results in decreased numbers of oligodendrocytes and myelin. In a similar manner, laminin-2 promotes myelin formation both in vitro and in vivo via a mechanism that is sensitive to pharmacological inhibition of the PI3K/Akt pathway and can be abrogated by a dominant-negative Akt mutant (Chun et al., 2003). Direct evidence implicating Akt signaling in OPC maturation derives from studies using targeted expression of a constitutive active Akt mutant in the oligodendrocyte lineage that stimulates premature and enhanced myelination of the CNS in the absence of an increased number of OPCs (Flores et al., 2008). Despite the evidence that Akt is involved in OPC maturation, the downstream targets of Akt that promote oligodendrocyte development are unknown.

The mammalian target of rapamycin (mTOR) is a serinethreonine kinase that functions as a key regulator of cell growth in response to PI3K/Akt stimulation and nutrient sensing. mTOR forms two distinct signaling complexes, termed mTORC1 and mTORC2, defined by its association with the adaptor proteins raptor or rictor, which regulate kinase specificity toward distinct downstream targets. mTORC1 is best characterized for its ability to regulate cell growth and protein translation via the phosphorylation of p70S6K1 and 4E-BPs (Kim et al., 2002; Hay and Sonenberg, 2004). Recently, mTORC2 was identified as the critical ki- 
nase for Akt Ser 473 phosphorylation (Sarbassov et al., 2005, 2006). mTORC2 also regulates the organization of the actin cytoskeleton in part by modulating the activity of PKC- $\alpha$ (Sarbassov et al., 2004). Together, these studies demonstrate that mTOR functions both as a signaling effector in response to PI3K/ Akt signaling, as well as a key modulator of Akt activity via mTORC2.

In this study, we demonstrate that mTOR is essential for oligodendrocyte differentiation. mTOR is activated during OPC differentiation in vivo and in vitro, and inhibiting $\mathrm{mTOR}$ arrests oligodendrocyte differentiation at the late progenitor stage. Finally, we provide evidence that mTORC1 and mTORC2 promote oligodendrocyte differentiation through distinct mechanisms.

\section{Materials and Methods}

Materials. Cell culture media (MEM, DMEM/F12), FBS, trypsin, and insulin-selenium-transferrin (ITS) were purchased from InvitrogenBRL. Additional N2 supplements, triiodothyronine, and poly-D-lysine were purchased from Sigma. Poly-D-lysine/laminin-coated coverslips were acquired from BD Biosciences. Recombinant human FGF-2 was purchased from R\&D Systems. Rapamycin was purchased from Calbiochem. Control and target validated siRNA smart pools were purchased from Dharmacon. Oligodendrocyte nucleofection kits were obtained from Amaxa/Lonza. Antibodies to myelin basic protein (MBP), proteolipid protein (PLP), and 2',3'-cyclic nucleotide $3^{\prime}$-phosphodiesterase (CNP) were purchased from Millipore Bioscience Research Reagents. Antibodies to mTOR, raptor, rictor, P-mTOR Ser 2448, P-p70S6K1 Thr 389, total p70S6K1, P-Akt Ser 473, total Akt, and active caspase-3 were purchased from Cell Signaling. Antibodies to 4E-BP were purchased from Bethyl Laboratories. Trizol reagent and Superscript III reverse transcriptase were purchased from Invitrogen. Validated QuantiTect primer sets and the QuantiTect SYBR green PCR detection kit were purchased from Qiagen. Vector NovaRED substrate kit for peroxidase was purchased from Vector Labs.

Primary cortical oligodendrocyte progenitor cultures and differentiation paradigm. All animal experimentation protocols were approved by the University of Medicine and Dentistry of New Jersey (UMDNJ) and Rutgers Institutional Animal Care and Use Committees (IACUC) and were conducted in accordance with the National Institutes of Health guidelines for the care and use of laboratory animals. OPCs were purified from cortical mixed glial cultures by established methods (McCarthy and de Vellis, 1980). Briefly, brains were removed from postnatal day 0-2 Sprague Dawley rat pups and the cortices were dissected. Cortical pieces were enzymatically digested in $2.5 \%$ trypsin and Dnase I followed by mechanical dissociation. Cells were resuspended in MEM-C, which consists of minimal essential medium (MEM) supplemented with 10\% FBS, L-glutamine, and 1\% Pen-strep, and plated onto T75 flasks. The resulting mixed glial cultures were maintained for $10 \mathrm{~d}$. Purified OPC cultures were prepared by a differential shake (McCarthy and de Vellis, 1980). Purified OPCs were seeded onto poly-D-lysine-coated T75 flasks at a density of $2 \times 10^{4}$ cells $/ \mathrm{cm}^{2}$ in a chemically defined medium (N2S). N2S consists of $66 \%$ N2B2 (DMEM/F12 supplemented with $0.66 \mathrm{mg} / \mathrm{ml} \mathrm{BSA}$, $10 \mathrm{ng} / \mathrm{ml} \mathrm{D}$-biotin, $5 \mu \mathrm{g} / \mathrm{ml}$ insulin, $20 \mathrm{nM}$ progesterone, $100 \mu \mathrm{M} \mathrm{pu}-$ trescine, $5 \mathrm{ng} / \mathrm{ml}$ selenium, $50 \mu \mathrm{g} / \mathrm{ml}$ apo-transferrin, $100 \mathrm{U} / \mathrm{ml}$ penicillin, $100 \mu \mathrm{g} / \mathrm{ml}$ streptomycin, and $0.5 \%$ FBS) supplemented with $34 \%$ B104 conditioned media, $5 \mathrm{ng} / \mathrm{ml} \mathrm{FGF}$, and $0.5 \%$ FBS. Purified OPCs were amplified for 4-10 $\mathrm{d}$ in N2S, passaged once with papain, and plated for experiments.

To initiate OPC differentiation, we followed an established mitogen withdrawal protocol (Tokumoto et al., 1999). Briefly, OPCs were seeded onto poly-D-lysine-coated dishes or round $12 \mathrm{~mm}$ poly-D-lysine/ laminin-coated cover-glass at a density of $2 \times 10^{4}$ cells $/ \mathrm{cm}^{2}$ in N2S media and allowed to recover overnight. The following day, N2S media were replaced with mitogen free N2B2 media supplemented with $30 \mathrm{ng} / \mathrm{ml}$ triiodothyronine (T3). For rapamycin treatments, a stock solution of rapamycin resuspended in ethanol was diluted into $\mathrm{N} 2 \mathrm{~B} 2+\mathrm{T} 3$ to a final concentration of $15 \mathrm{~nm}$. Control cultures received vehicle alone $(0.002 \%$ ethanol). N2B2+T3 differentiation media with or without rapamycin was replenished every $48 \mathrm{~h}$ during the course of experiments.

Immunocytochemistry and in vitro quantification. Purified OPCs were plated onto round $12 \mathrm{~mm}$ poly-D-lysine/laminin-coated coverglass in N2S media at a density of $2 \times 10^{4}$ cells $/ \mathrm{cm}^{2}$ and allowed to recover overnight. The following day, differentiation in the presence or absence of rapamycin at the indicated doses was initiated by mitogen withdrawal in N2B2+T3 differentiation media. After 1, 2, 3.5, or $5 \mathrm{~d}$ of differentiation, the coverslips were fixed with $2 \%$ paraformaldehyde for $8 \mathrm{~min}$ followed by three washes in PBS. A blocking step was performed by incubating the coverslips in diluent (PBS containing 10\% fetal calf serum and $10 \%$ lamb serum) for 15 min. Detection of R24, O4, and GalC cell surface antigens was performed by diluting supernatant from the R24 hybridoma, O4 hybridoma, and Ranscht hybridoma 1:2, 1:3, and 1:2 respectively in diluent and added to the coverslips for $45 \mathrm{~min}$ at room temperature. Coverslips were washed again in PBS and incubated in diluent containing $4^{\prime}, 6^{\prime}$-diamidino-2-phenylindole dihydrochloride (DAPI; 1:1000), goat anti-mouse-IgM fluorescein isothiocyanate (FITC; 1:500), and goat anti-mouse-IgG3 tetramethylrhodamine isothiocyanate (TRITC; 1:250) secondary antibodies for $45 \mathrm{~min}$ to detect O4 and GalC or R24 respectively. Finally, coverslips were washed 3 times in PBS and mounted on superfrost slides with Aquamount containing 2.5\% DABCO. To detect PLP, cells were permeabilized with $0.1 \%$ Triton $\mathrm{X}-100$ for 4 min after fixation in $2 \%$ paraformaldehyde. The anti-PLP antibody (Millipore Bioscience Research Reagents) was diluted 1:100 in diluent and incubated as described above, followed by incubation with goat anti-mouse-IgG FITC secondary antibodies.

To quantify the number of $\mathrm{O}_{4}^{+} / \mathrm{GalC}^{+}$immature oligodendrocytes present in our cultures after 3.5 and $5 \mathrm{~d}$ of differentiation, cell counts were performed on a minimum of 6 independent fields ( 2 fields $/ 3$ coverslips/treatment) of photomicrographs captured with a $20 \times$ objective. Total counts of O4- and GalC-immunoreactive cells were performed, and the number of immature oligodendrocytes per culture was expressed as the percentage of $\mathrm{GalC}^{+}$cells to total $\mathrm{O}^{+}$cells.

Transfection of siRNA smart pools. For siRNA smart pool transfections, $5 \times 10^{6}$ OPCs were collected and resuspended in $100 \mu \mathrm{l}$ of rat oligodendrocyte nucleofector solution (Amaxa). Control, mTOR, rictor, or raptor targeting siRNA smart pools (200 pmols) were added to the cell suspension and transferred to an Amaxa certified cuvette. Cells were electroporated with the Amaxa nucleofection device using a protocol, O-17, optimized for the transfection of primary rat oligodendrocytes. After electroporation, cells were resuspended in N2S media and plated on poly-D-lysine-coated dishes. Cells were allowed to attach and recover overnight in N2S media. The following day, differentiation was initiated in N2B2+T3 media, and cells were cultured for 4 or $5 \mathrm{~d}$ before protein isolation.

Protein isolation and Western immunoblotting. After treatments, cells were washed twice with ice-cold PBS and total cell lysates were harvested in $2 \times$ SDS lysis buffer [ $125 \mathrm{~mm}$ Tris-HCl, $4 \%$ SDS, 20\% glycerol, $100 \mathrm{~mm}$ DTT, $1 / 50$ protease inhibitor (PI) cocktail (Sigma)]. The lysates were briefly sonicated and stored at $-80^{\circ} \mathrm{C}$ before Western analysis. The RC-DC protein assay (Bio-Rad) was performed to determine protein concentration. $\sim 15 \mu \mathrm{g}$ of total protein per sample was aliquoted, boiled for $5 \mathrm{~min}$ and separated by SDS-PAGE on Bis-Tris mini-gels (Invitrogen). Separated proteins were then transferred to nitrocellulose membranes and blocked in 5\% milk/TBS- $0.1 \%$ Tween for $1 \mathrm{~h}$ at room temperature. Membranes were then incubated in the presence of primary antibodies diluted in $5 \%$ milk/TBS- $0.1 \%$ Tween overnight at $4^{\circ} \mathrm{C}$. The following day, membranes were washed 3 times for $5 \mathrm{~min}$ with TBS- $0.1 \%$ Tween and incubated for $1 \mathrm{~h}$ at room temperature in 5\% milk/TBS- $0.1 \%$ Tween containing goat anti-rabbit or goat anti-mouse secondary antibodies at a dilution of 1:5000. The detection of HRP conjugated secondary antibodies was performed by enhanced chemiluminescence using the Ultra-LUM imaging device. Protein expression levels were quantified using NIH Image 1.62.

RNA isolation and $q P C R$ analysis. For RNA isolation, primary rat OPCs were seeded onto poly-D-lysine-coated $150 \mathrm{~mm}$ dishes in N2S media at a density of $2 \times 10^{4} \mathrm{cells} / \mathrm{cm}^{2}$. The following day, differentiation was initiated in the presence or absence of $15 \mathrm{~nm}$ rapamycin in 
$\mathrm{N} 2 \mathrm{~B} 2+\mathrm{T} 3$ differentiation media. On day 3 of differentiation, cells were washed twice in PBS, harvested in $500 \mu \mathrm{l}$ of PBS, and pelleted by centrifugation at $10,000 \times g$ for $10 \mathrm{~min}$. The supernatant was aspirated and cell pellets were stored at $-80^{\circ} \mathrm{C}$ before RNA isolation.

Frozen cell pellets were briefly thawed on ice and resuspended in $1 \mathrm{ml}$ of Trizol reagent (Invitrogen). Total RNA was extracted following the TRIZOL isolation protocol. Precipitated total RNA was resuspended in $50 \mu \mathrm{l}$ of nuclease free water and stored at $-80^{\circ} \mathrm{C}$. RNA concentration was measured using a NanoDrop spectrophotometer (Thermo Scientific). One microgram of total RNA was treated with Dnase I (Invitrogen) and used to generate cDNA. First strand cDNA was synthesized using Superscript III reverse transcriptase (Invitrogen). Concentrations of cDNA were determined by spectrophotometry and stored at $-20^{\circ} \mathrm{C}$ before $\mathrm{qPCR}$ analysis.

For qPCRs, $150 \mathrm{ng}$ of cDNA was used as template in each reaction containing $1 \times$ SYBR green detection master mix and $1 \times$ QuantiTect primer mix to detect the mRNA expression levels of MBP, PLP, Ugt-8, Sox10, Olig2, Nkx2.2, Tcf4, Id2, or Id4 (Qiagen). Amplification levels were normalized to expression levels of $\beta$-actin for each sample. The qPCRs were performed on the Applied Biosystems 7900HT Fast Realtime PCR system using associated Sequence Detection Systems Software Version 2.2.2 (SDS2.2.2). The thermal reaction profiles for the PCRs were performed as follows: $50^{\circ} \mathrm{C}$ for $2 \mathrm{~min}, 9^{\circ} \mathrm{C}$ for $10 \mathrm{~min}, 40$ cycles of $95^{\circ} \mathrm{C}$ for $15 \mathrm{~s}$, and $58^{\circ} \mathrm{C}$ for $1 \mathrm{~min}$.

Coimmunoprecipitations of mTORC1 and mTORC2 complexes. Primary rat OPCs were plated on poly-D-lysine-coated $100 \mathrm{~mm}$ dishes in N2S media. The following day, differentiation was initiated by mitogen withdrawal in N2B2+T3 differentiation media in the presence or absence of $15 \mathrm{~nm}$ rapamycin. On days 1 and 2 of differentiation, cells were washed twice with cold PBS, harvested in $500 \mu \mathrm{l}$ of PBS, and pelleted by centrifugation at $10,000 \times g$ for $5 \mathrm{~min}$ at $4^{\circ} \mathrm{C}$. Cells from (6) $100 \mathrm{~mm}$ dishes were pooled for each treatment group. Cell pellets were resuspended and lysed in $1 \mathrm{ml}$ of immunoprecipitation (IP) buffer for $30 \mathrm{~min}$ on ice. IP buffer was composed of 40 mM HEPES, pH 7.5, $120 \mathrm{~mm} \mathrm{NaCl}$, $1 \mathrm{~mm}$ EDTA, $10 \mathrm{~mm}$ pyrophosphate, $50 \mathrm{~mm} \mathrm{NaF}, 0.5 \mathrm{~mm}$ orthovanadate, protease inhibitors, and $1 \%$ Triton X-100. A portion of the lysate was used to determine protein concentration by the DC protein assay (Bio$\mathrm{Rad})$. A total of $600 \mu \mathrm{g}$ of protein was used for each immunoprecipitation per treatment group. The lysates were precleared by incubation with $30 \mu \mathrm{l}$ of protein $\mathrm{A} / \mathrm{G}$ agarose at $4^{\circ} \mathrm{C}$ followed by centrifugation at $10,000 \times g$ for $5 \mathrm{~min}$. Primary antibodies to $\mathrm{mTOR}(2 \mu \mathrm{g}$ total $)$ were added to the supernatants and incubated with gentle rotation overnight at $4^{\circ} \mathrm{C}$. The following day $30 \mu \mathrm{l}$ of protein $\mathrm{A} / \mathrm{G}$ agarose beads was added to the lysates and incubated for $4 \mathrm{~h}$. Immune complexes were precipitated by centrifugation at $8000 \times g$ for $5 \mathrm{~min}$ and washed three times with ice-cold IP buffer. Immune complexes were resuspended in $30 \mu \mathrm{l}$ of $1 \times$ SDS lysis buffer and boiled for $5 \mathrm{~min}$. Samples were separated on 3-8\% Tris-acetate gels by SDS-PAGE, transferred to nitrocellulose membranes that were subsequently probed with antibodies to detect mTOR, raptor, and rictor.

Delayed addition of rapamycin. Primary rat OPCs were plated on round $12 \mathrm{~mm}$ poly-D-lysine/laminin-coated coverslips in 24 well dishes in N2S media at a density of $2 \times 10^{4}$ cells $/ \mathrm{cm}^{2}$. The following day, differentiation was initiated by the addition of N2B2 + T3 differentiation media with or without $15 \mathrm{~nm}$ rapamycin. A total volume of $600 \mu \mathrm{l}$ of media was added to each well. For delayed treatments, a $10 \times$ stock of rapamycin or vehicle alone was prepared in DMEM/F12 that was diluted directly into the media on 1,2,3, or $4 \mathrm{~d}$ of differentiation to achieve a final concentration of $15 \mathrm{~nm}$ rapamycin. The media for each treatment group were replenished every $48 \mathrm{~h}$ for the duration of the experiment. On day 5 of differentiation, coverslips were washed 3 times in PBS and prepared for the immunocytochemical detection of $\mathrm{O} 4$ and GalC cell surface antigens as described. Total numbers of GalC-positive immature oligodendrocytes were quantified as described in previous experiments.

IHC detection of $p-m$ TOR Ser 2448 in vivo. For developmental analyses of mTOR Ser 2448 phosphorylation in vivo, postnatal day 14, 18, and 21 rat pup littermates were anesthetized via IP injection of a 3:1 mixture of ketamine and xylazine. Brains were fixed by transcardiac perfusion with $3 \%$ paraformaldehyde and extracted. Extracted brains were further immersed in $3 \%$ paraformaldehyde for $4 \mathrm{~h}$ at $4^{\circ} \mathrm{C}$. Brains were blocked in a coronal plane, placed in tissue cassettes, and stored in 70\% ethanol before paraffin embedding. A total of $205 \mu \mathrm{m}$ sections, two per slide, were prepared from each paraffin embedded tissue sample.

For IHC detection, sections were deparaffinized and rehydrated through ethanols. Sections were then incubated in 3\% hydrogen peroxide in methanol for $10 \mathrm{~min}$ at room temperature and rinsed several times with Tris buffered saline (TBS). Antigen retrieval was performed by incubation in proteinase $\mathrm{K}(5 \mu \mathrm{g} / \mathrm{ml})$ in $10 \mathrm{~mm}$ Tris, $\mathrm{pH}$ 8.0, for $10 \mathrm{~min}$ at $37^{\circ} \mathrm{C}$. Next, the sections were rinsed in TBS and permeabilized in $0.3 \%$ Triton X-100 in TBS for $30 \mathrm{~min}$ at room temperature. Sections were then blocked in TGB superblock ( $0.5 \mathrm{M}$ Tris PH 7.6, 10\% BSA, 10\% goat serum, $0.05 \% \mathrm{NaN}_{3}$ ) for $1 \mathrm{~h}$ at room temperature. Primary antibodies to p-mTOR Ser 2448 (Cell Signaling; 1:250) were diluted in TGB diluent (0.5 м TBS, $20 \%$ TGB superblock, and $0.2 \%$ Triton X-100) and incubated overnight in a humid chamber at $4^{\circ} \mathrm{C}$. The following day, sections were washed and incubated in TGB diluent containing Goat anti-Rabbit biotinylated secondary antibodies for $2 \mathrm{~h}$ at $37^{\circ} \mathrm{C}$. Next, the sections were washed and incubated in streptavidin-HRP in TBS plus 10\% bovine serum $2 \mathrm{~h}$ at $37^{\circ} \mathrm{C}$. HRP detection was visualized with NovaRed substrate (Vector Labs). Sections were briefly counterstained with hematoxylin, dehydrated, and coverslipped with cytoseal mounting medium. Photomicrographs of each section were captured using a $20 \times$ objective.

Dorsal root ganglion neuron-OPC cocultures. Dorsal root ganglion (DRG) neurons were dissected from E14.5-E16.5 rat embryos and were dissociated in $0.25 \%$ trypsin (Invitrogen) for $30 \mathrm{~min}$ at $37^{\circ} \mathrm{C}$. The dissociated DRGs were plated onto $12 \mathrm{~mm}$ glass coverslips coated with growth factor reduced Matrigel (1:10 dilution; Invitrogen) (1 DRG/coverslip) in DMEM (Mediatech) and 10\% fetal bovine serum (FBS) (Mediatech) supplemented with $50 \mathrm{ng} / \mathrm{ml}$ nerve growth factor (NGF) (Harlan) in a $140 \mu \mathrm{l}$ droplet. To remove the proliferating non-neuronal cells, $6-8 \mathrm{~h}$ after plating, the cultures were flooded in DMEM with 10\% FBS supplemented with $50 \mathrm{ng} / \mathrm{ml} \mathrm{NGF}$ containing $15 \mu \mathrm{M}$ fluorodeoxyuridine (FUdR). Two days later, the media were replaced with Neurobasal medium (Invitrogen) supplemented with 2\% B27 supplement mixture (Invitrogen) containing $10 \mu \mathrm{M}$ FUdR. FUdR was removed from the medium after an additional $2 \mathrm{~d}$ and cultures were maintained in Neurobasal medium with the supplements for $2 \mathrm{~d}$ before switching to DMEM and $10 \%$ FBS supplemented with $50 \mathrm{ng} / \mathrm{ml} \mathrm{NGF}$. Cultures were maintained under the same condition for another $4-5 \mathrm{~d}$ with the media changed every $2 \mathrm{~d}$.

OPCs were purified from mixed glial cortical cultures as described above. The OPCs were trypsinized and plated onto DRG neurons at a density of 350,000 - 400,000 cells/coverslip in DMEM and 10\% FBS supplemented with $50 \mathrm{ng} / \mathrm{ml}$ NGF. Media were changed every $2 \mathrm{~d}$ and oligodendrocyte differentiation and myelination in the cocultures were assessed on day 7 or day 18. After immunostaining, images from 30 random fields/coverslip were taken using a $60 \times$ objective. From each image, the numbers of MBP-positive myelin segments, MBP-positive oligodendrocytes, and DAPI-positive cells were determined. The level of myelination was determined as total number of MBP-positive segments as a percentage of total number of DAPI-positive cells per field. Differentiation of oligodendrocytes was quantified by total number of MBPpositive oligodendrocytes as a percentage of total number of DAPIpositive cells.

Neurosphere preparation and differentiation. Normal Wistar pups [postnatal day 2-7 (P2-P7)] were killed by decapitation and their brains removed using aseptic techniques. The subventricular zones (SVZs) were isolated and placed in dishes containing PGM solution (PBS with $1 \mathrm{~mm}$ $\mathrm{MgCl}_{2}$ and $0.6 \%$ dextrose), where the SVZ was mechanically minced. The pieces of tissue were collected and incubated in $0.05 \%$ trypsin solution at $37^{\circ} \mathrm{C}$ for $5 \mathrm{~min}$. The tissue was dissociated in Pro- $\mathrm{N}$ media (DMEM/F12 media containing $10 \mathrm{ng} / \mathrm{ml}$ D-biotin, $25 \mu \mathrm{g} / \mathrm{ml}$ insulin, 6.29 $\mathrm{ng} / \mathrm{ml}$ progesterone, $16.11 \mu \mathrm{g} / \mathrm{ml}$ putrescine, $5 \mathrm{ng} / \mathrm{ml}$ selenium, $50 \mu \mathrm{g} / \mathrm{ml}$ apo-transferrin; Sigma Aldrich), $50 \mu \mathrm{g} / \mathrm{ml}$ gentamycin (Invitrogen) using micropipettes. The cell suspension was then passed through a $40 \mu \mathrm{m}$ Nitex screen to ensure an even single cell suspension and cells were collected by centrifugation at $200 \times g$ for $5 \mathrm{~min}$. The media were removed and replaced with $10 \mathrm{ml}$ of fresh media and the process repeated 3 times to remove tissue debris. The number of viable cells was determined with a hemocytometer by exclusion of $0.1 \%$ Trypan Blue dye. The cells were 
then plated into 12-well tissue culture plastic plates (BD Biosciences) at a density of $1 \times 10^{5}$ cells $/ \mathrm{ml}$ in Pro-N media supplemented with 20 $\mathrm{ng} / \mathrm{ml}$ EGF (R\&D Systems) and $10 \mathrm{ng} / \mathrm{ml} \mathrm{FGF-2}$ (R\&D Systems). Cell cultures were fed every 2 to $3 \mathrm{~d}$. After $6-7 \mathrm{~d}$, the primary neurospheres were collected and passaged to form secondary neurospheres. Neurospheres were collected and centrifuged at $200 \mathrm{~g}$ for $5 \mathrm{~min}$. The media was removed, replaced with Accutase (Innovative Cell Technology) and incubated at $37^{\circ} \mathrm{C}$ for 5 $\mathrm{min}$. The spheres were dissociated in Pro- $\mathrm{N}$ media using micropipettes. The cell suspension was then passed through a $40 \mu \mathrm{m}$ Nitex screen and cells were collected by centrifugation at $200 \times g$ for $5 \mathrm{~min}$. The media were removed and replaced with $10 \mathrm{ml}$ of fresh media and the process repeated 3 times. Viable cells were then plated into $60 \mathrm{~mm}$ dishes (BD Biosciences) at a density of $1 \times 10^{5}$ cells $/ \mathrm{ml}$ in 50/50 mixture of Pro-N media supplemented with $20 \mathrm{ng} / \mathrm{ml} \mathrm{EGF} \mathrm{(R \& D} \mathrm{Systems)} \mathrm{and}$ $10 \mathrm{ng} / \mathrm{ml}$ FGF-2 (Alomone Labs, Israel) and neurosphere conditioned Pro-N media. Cell cultures were fed every $2 \mathrm{~d}$. This protocol has been previously shown to yield NSPs (Felling et al., 2006).

For differentiation experiments, secondary neurospheres were cultured for $10 \mathrm{~d}$ before being dissociated to ensure large neurospheres that would contain neural progenitors. Neurospheres were collected and centrifuged at $200 \mathrm{~g}$ for $5 \mathrm{~min}$. The media were removed, replaced with Accutase (Innovative Cell Technology) and incubated at $37^{\circ} \mathrm{C}$ for $5 \mathrm{~min}$. The spheres were dissociated in Pro- $\mathrm{N}$ media using micropipettes. The cell suspension was then passed through a $40 \mu \mathrm{m}$ Nitex screen and cells were collected by centrifugation at $200 \mathrm{~g}$ for $5 \mathrm{~min}$. The media were removed and replaced with $10 \mathrm{ml}$ of fresh media and the process repeated three times. Viable cells were then plated into either 60 $\mathrm{mm}$ dishes (BD Biosciences) or chamber slides pretreated with poly-Dlysine $(20 \mu \mathrm{g} / \mathrm{ml}) / \mathrm{laminin}(10 \mu \mathrm{g} / \mathrm{ml})$ at a density of $5 \times 10^{5}$ cells $/ \mathrm{ml}$.

Secondary neurospheres were cultured in either N2B3 media or N2B3 media supplemented with $10 \mathrm{~nm}$ rapamycin for $7 \mathrm{~d}$ in vitro to allow for complete differentiation. The cells were fed every second day.

\section{Results \\ Phosphorylation of mTOR Ser 2448 correlates with myelination in vivo}

In response to PI3K/Akt stimulation, mTOR is phosphorylated on serine 2448, which correlates with increased kinase activity (Sekulić et al., 2000; Choe et al., 2003; Holz and Blenis, 2005). To determine whether $\mathrm{mTOR}$ is active during OPC differentiation in vivo, we detected phosphorylated mTOR on Ser 2448 by performing IHC on the subcortical white matter (WM) during postnatal rat CNS development (Fig. 1). p-mTOR Ser 2448 was apparent in WM by postnatal day 14 (Fig. $1 A$ ), became more abundant in subcortical and striatal WM by postnatal day 18 (Fig. $1 B$ ) and further intensified through day 21 (Fig. 1C). Thus, mTOR phosphorylation increased as myelination peaked in the forebrain (Hamano et al., 1996). In addition, p-mTOR is detected in rows of interfascicular oligodendrocytes in the corpus callosum and in $\mathrm{MBP}^{+}$cells (Fig. $1 D, F$ ), but is not detected in $\mathrm{GFAP}^{+}$astrocytes (Fig. 1G).

\section{Inhibitng mTOR decreases morphological complexity during OPC differentiation}

Oligodendrocyte differentiation is characterized in part by the transition from a simple bipolar morphology to a complex

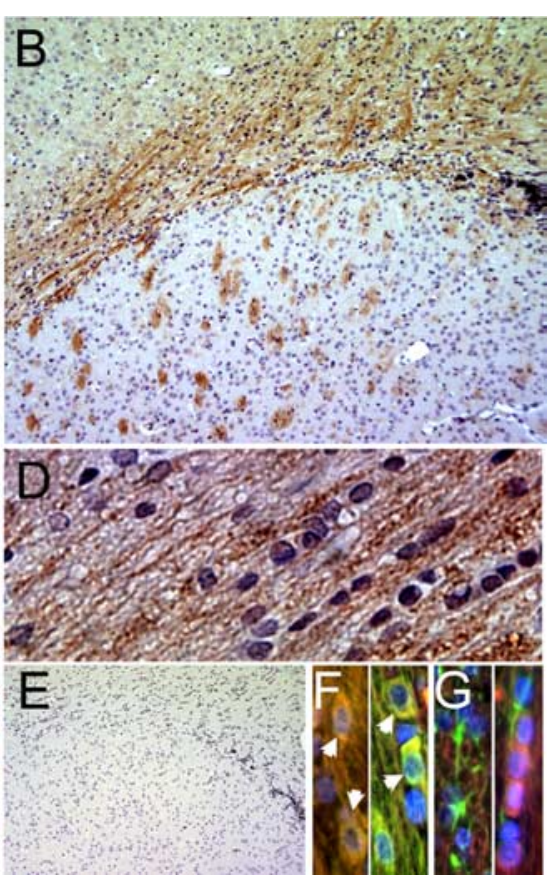

Figure 1. $\quad \mathrm{HC}$ (detection of p-mTOR Ser 2448 in subcortical white matter during postnatal rat CNS development. $A-C$, Fixed, paraffin(a) ( ), and DAPI in corpus callosum. Panels show two fields with colocalization of p-mTOR and MBP (arrowheads). G, Immunostaining of p-mTOR (TRITC), GFAP (FITC), and DAPI in corpus callosum. Panels show GFAP and p-mTOR in separate cells in two fields.

branched morphology. To determine whether mTOR regulates the morphological progression of OPCs during differentiation in vitro, we examined cultures of OPCs by phase contrast microscopy. After $2 \mathrm{~d}$ of differentiation, control and rapamycin treated cells displayed increased branching compared with undifferentiated early progenitors (Fig. $2 A, B$ ). Control cultures contained a mixed population of simple branched cells, characteristic of $\mathrm{O}^{+} / \mathrm{GalC}^{-}$late progenitors, as well as complex multipolar oligodendrocytes which extended an elaborate network of lacy processes (Fig. 2A). However, very few complex multipolar oligodendrocytes were observed in rapamycin treated cultures (Fig. $2 B$ ). Instead, rapamycin treated cells exhibited a simple multipolar morphology characteristic of the late progenitor stage of differentiation.

\section{mTOR is required for the appearance of $\mathrm{GalC}^{+}$ oligodendrocytes in vitro}

To determine directly whether inhibiting mTOR prevents oligodendrocyte differentiation past the late progenitor stage, we performed immunocytochemistry for the stage-specific cell surface antigens $\mathrm{O} 4$ and GalC. Cortical OPC cultures were cultured in the absence of mitogens $\pm 15 \mathrm{~nm}$ rapamycin for $3.5 \mathrm{~d}$, and the total numbers of $4^{+} / \mathrm{GalC}^{-}$late progenitors and $\mathrm{O}^{+} / \mathrm{GalC}^{+}$ immature oligodendrocytes were quantified. Control and rapamycin treated OPCs gained the expression of $\mathrm{O} 4$ by $3.5 \mathrm{~d}$ (Fig. $2 E, F)$. In addition, $\sim 30 \%$ of cells in control cultures were identified as $\mathrm{GalC}^{+}$immature oligodendrocytes (Fig. 2C,G). However, inhibiting mTOR with rapamycin caused a significant reduction in the number of $\mathrm{GalC}^{+}$cells $(<1 \%, \mathrm{p}<0.0001)$ (Fig. $2 D, G)$, effectively blocking the progression of OPC differentiation at the late progenitor stage.

To demonstrate that rapamycin blocked rather than delayed differentiation, we repeated immunocytochemistry for $\mathrm{O} 4$ and 

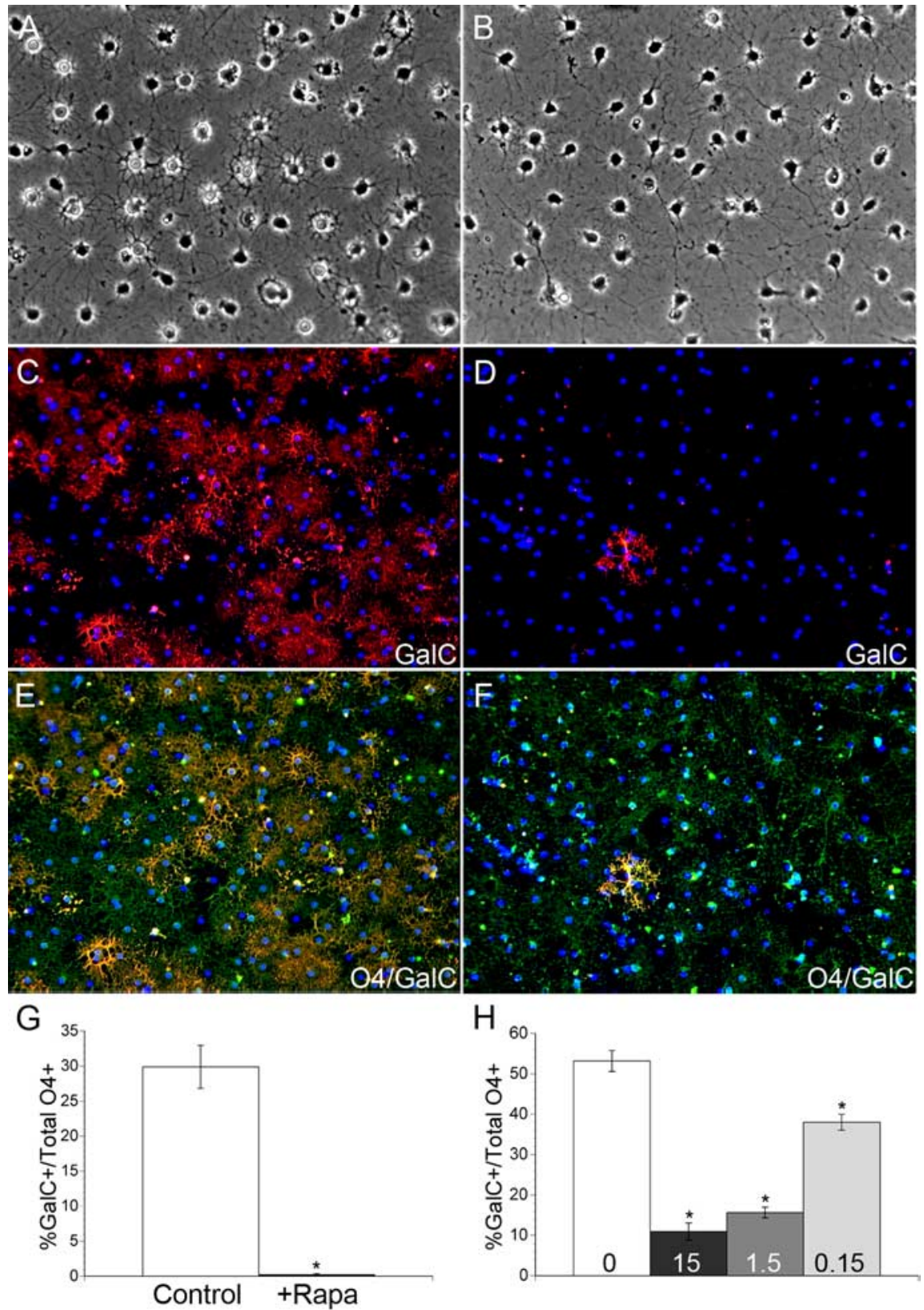

Figure 2. Inhibition of mTOR by rapamycin blocks OPC differentiation at the $04^{+} / \mathrm{GalC}^{-}$late progenitor stage. $\boldsymbol{A}, \boldsymbol{B}$, Phase contrast images of control cultures after $2 \mathrm{~d}$ of differentiation $(\boldsymbol{A})$, and cultures treated with $15 \mathrm{~nm}$ rapamycin for $2 \mathrm{~d}(\boldsymbol{B}) . \boldsymbol{C}-\boldsymbol{F}$, Representative images of GaIC (TRITC) (C, D) or 04 (FITC)/GaIC (TRITC) (E, F) IHC performed on OPC cultures differentiated in the absence (C, $\boldsymbol{E}$ ) or presence $(\boldsymbol{D}, \boldsymbol{F})$ of $15 \mathrm{~nm}$ rapamycin for $3.5 \mathrm{~d}$. $\mathbf{G}, \boldsymbol{H}$, Quantification of the percentage of $\mathrm{GalC}{ }^{+}$immature oligodendrocytes in control versus $15 \mathrm{~nm}$ rapamycin-treated cultures after $3.5 \mathrm{~d}$ of differentiation $\left(\boldsymbol{G} ;{ }^{*} p<0.0001\right)$ or after $5 \mathrm{~d}$ of differentiation in control versus rapamycin treatments of $15 \mathrm{~nm}, 1.5 \mathrm{~nm}$, and $0.15 \mathrm{~nm}\left(\boldsymbol{H} ;{ }^{*} p<0.0001 \mathrm{vs}\right.$ (tl for all doses of rapamycin).

GalC after $5 \mathrm{~d}$ of differentiation. On day 5 of differentiation, $\sim 50 \%$ of the OPCs in control cultures reached the $\mathrm{GalC}^{+}$immature oligodendrocyte stage (Fig. $2 H$ ). However, $<10 \%$ of the OPCs treated with $15 \mathrm{~nm}$ rapamycin progressed past the late progenitor stage (Fig. $2 H)(p<0.0001)$. In addition, we performed a dose-response to determine the sensitivity of the transition to the $\mathrm{O}^{+} / \mathrm{GalC}^{+}$immature oligodendrocyte stage to mTOR inhibition. Doses of rapamycin as low as $0.15 \mathrm{nM}$ caused a $28 \%$ reduction $(p<0.0001)$ in the number of OPCs that progressed past the $\mathrm{O}^{+} / \mathrm{GalC}^{-}$late progenitor stage (Fig. $2 \mathrm{H}$ ).

To demonstrate that inhibiting mTOR has no effect on early stages of OPC differentiation, we performed immunocytochem- istry for R24, which labels early progenitors, and $\mathrm{O} 4$ after 1 and 2 d of differentiation $\pm 15 \mathrm{~nm}$ rapamycin. The percentages of $\mathrm{R}_{2} 4^{+}$early progenitors and $\mathrm{O}^{+}$late progenitors were quantified. Rapamycin had no effect on the numbers of $\mathrm{R} 24^{+}$or $\mathrm{O} 4{ }^{+}$cells in the cultures on day 1 (supplemental Fig. $1 A-C$, available at www. jneurosci.org as supplemental material) or day 2 of differentiation (supplemental Fig. $1 D-F$, available at www.jneurosci.org as supplemental material).

\section{mTOR regulates the expression of myelin proteins MBP and PLP}

To provide further evidence that mTOR activation is required for OPCs to progress past the late progenitor stage, we examined the expression of MBP and PLP. By $5 \mathrm{~d}$ of differentiation, a significant number of PLP-positive oligodendrocytes were present in control cultures (Fig. $3 A, C$ ). However, inhibiting mTOR completely blocked the acquisition of PLP (Fig. $3 B, D$ ). Western blot analysis of MBP expression during a differentiation time course showed a robust increase in MBP expression in control cultures after $4 \mathrm{~d}$ of differentiation that was completely abrogated by mTOR inhibition (Fig. $3 E$ ).

Although rapamycin is a specific inhibitor of mTOR, we performed siRNA mediated knockdown of mTOR expression to independently confirm that the effects of rapamycin on OPC differentiation were a result of inhibiting mTOR activity. OPCs were transiently transfected with either a control or mTOR-targeting siRNA smart pool. One day after transfection, the cells were cultured for $4 \mathrm{~d}$ in differentiation medium and levels of MBP expression were quantified as an index of differentiation. In cultures transfected with control siRNAs, marked MBP expression was apparent by $4 \mathrm{~d}$ of differentiation (Fig. $3 F$ ). In contrast, transfection with a siRNA smart pool targeting mTOR inhibited MBP expression (Fig. 3F).

\section{mTOR regulates $\mathrm{mRNA}$ expression of myelin genes}

Our previous studies demonstrated that inhibiting mTOR significantly reduced protein levels of MBP and PLP. To gain insight into the mechanisms by which $\mathrm{mTOR}$ regulates myelin protein expression, we measured MBP and PLP mRNA levels by quantitative PCR. A previous report showed that the mRNA levels for MBP and PLP are at or near peak levels by $3 \mathrm{~d}$ of differentiation in vitro (Dugas et al., 2006). Thus, total RNA isolated from control and rapamycin treated cultures after $3 \mathrm{~d}$ of differentiation was used to generate cDNA that was subjected to a validated QuantiTect primer assay (Qiagen) for MBP and PLP. Inhibiting mTOR by rapamycin resulted in an $84 \%$ and $64 \%$ reduction in $\mathrm{MBP}$ and PLP mRNA levels, respectively (Fig. 3G) (MBP, $p=0.0032$; PLP, 


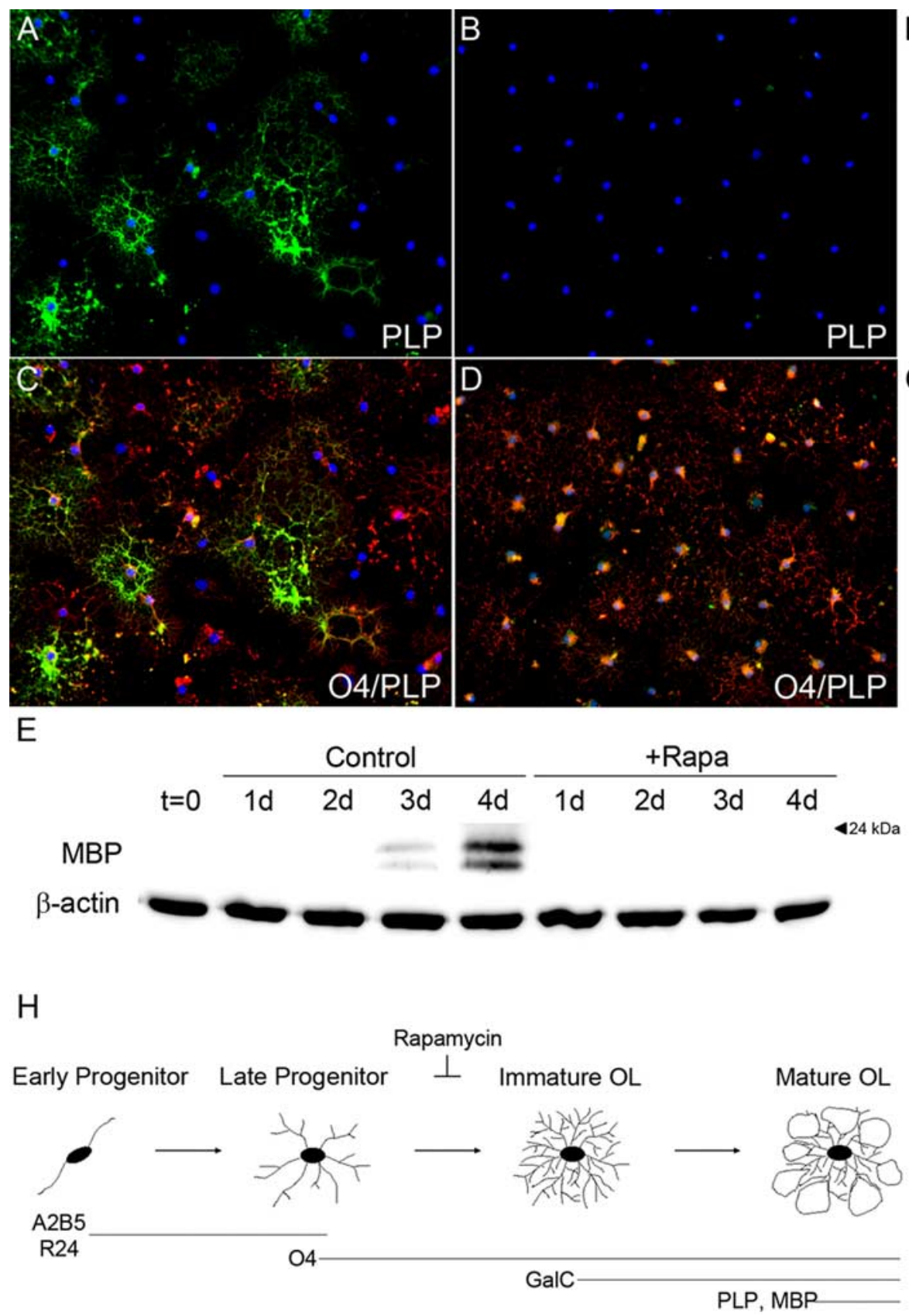

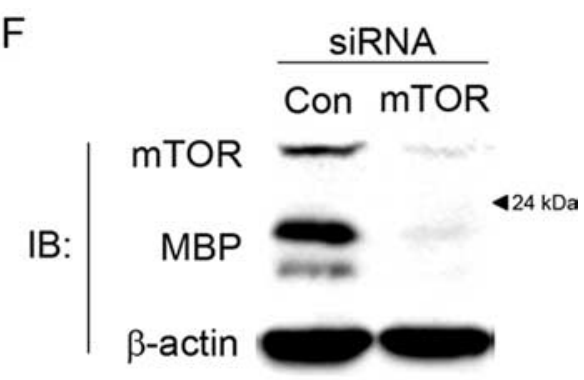

4 days
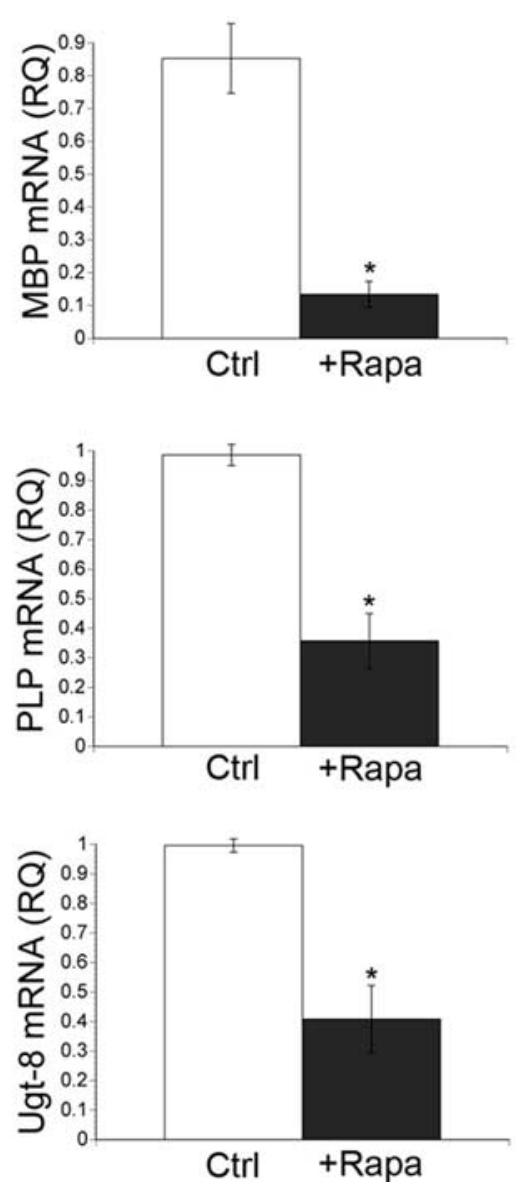

Figure 3. mTOR regulates the expression of myelin genes. $\boldsymbol{A}-\boldsymbol{D}$, Representative images of PLP (FITC) IHC are shown for OPCs differentiated in the absence $(\boldsymbol{A}, \boldsymbol{C})$ and presence $(\boldsymbol{B}, \boldsymbol{D})$ of $15 \mathrm{~nm}$ rapamycin for $5 \mathrm{~d}$. $\boldsymbol{E}$, Western immunoblot analysis of MBP expression during 4 consecutive days of OPC differentiation $\pm 15 \mathrm{~nm}$ rapamycin. $\boldsymbol{F}$, Western immunoblot analysis of MBP expression in OPCs transfected with control or mTOR smart pool siRNAs and cultured under differentiation conditions for 4 d. G, qPCR analysis of MBP, PLP, and Ugt-8 expression on day 3 of differentiation \pm 15 nм rapamycin. Rapamycin caused a significant reduction in the mRNA levels of MBP and PLP (MBP, ${ }^{*} p=0.0032 ; \mathrm{PLP},{ }^{*} p=0.0032$, Ugt- $\left.8,{ }^{*} p=0.0014\right)$. $\boldsymbol{H}$, Schematic of OPC differentiation. Inhibiting $\mathrm{mTOR}$ blocks the progression of OPC differentiation at the late progenitor stage.

$p=0.0032)$. Similar results were seen for CNPase mRNA levels (data not shown).

In addition, we measured the mRNA levels of UDP glycosyltransferase 8 (Ugt-8) after $3 \mathrm{~d}$ of differentiation in the presence or absence of rapamycin. Ugt- 8 catalyzes the final step in the biosynthesis of cerebrosides (Koul et al., 1980), a major component of myelin membranes, and also is upregulated during oligodendrocyte differentiation (Dugas et al., 2006). Inhibiting mTOR decreased Ugt- 8 mRNA by $58 \%$ after $3 \mathrm{~d}$ of differentiation (Fig. $3 G)(p=0.0014)$.

\section{CNPase expression but not Tuj1 or GFAP expression} decreases in the presence of rapamycin

To determine whether mTOR participates in the differentiation of neurons and astrocytes, we added rapamycin during the differentiation of neural stem/progenitor (NSP) cells dissociated from neonatal SVZ-derived neurospheres. After $7 \mathrm{~d}$ of differentiation, CNPase expression was decreased whereas neither Tuj1 nor GFAP were altered (supplemental Fig. $2 A-C$, available at www.jneurosci.org as supplemental material). Consistent with the reduction in CNPase, immunostaining for O1 was similarly 
A

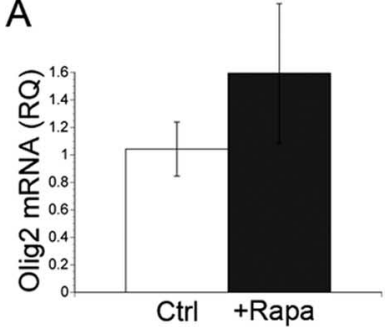

B

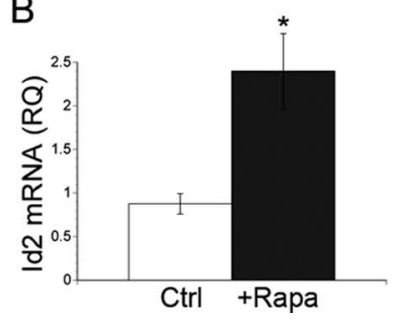

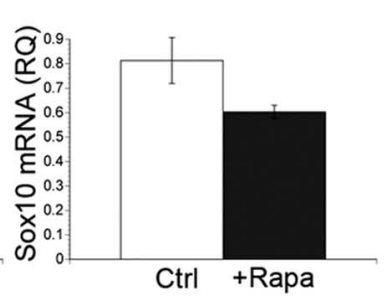

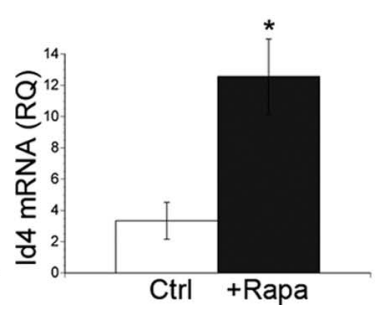

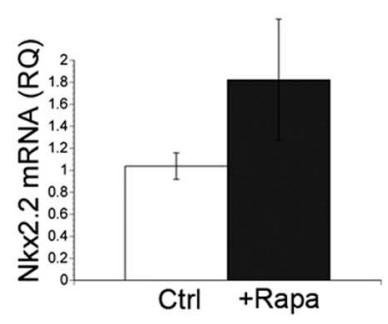

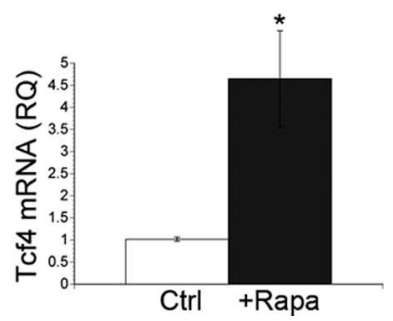

Figure 4. $\mathrm{mTOR}$ selectively regulates transcription factor activity during $0 \mathrm{~L}$ differentiation. Total RNA was extracted from $0 \mathrm{PCS}$ after $3 \mathrm{~d}$ of differentiation $\pm 15 \mathrm{~nm}$ rapamycin. $A$, 0lig2, Sox10, or Nkx2.2 mRNA levels were quantified using validated QuantiTect primer assays (Qiagen). Rapamycin treatment did not significantly affect alter the mRNA levels of Olig2, Sox10, or Nkx 2.2. B, Id2, Id4, or Tcf4 mRNA levels were quantified using validated QuantiTect primer assays (Qiagen). Inhibition of mTOR caused a 2.7-fold, 3.8-fold, and 4.6-fold increase in the mRNA levels of Id, Id4, and Tcf4, respectively (Id2, ${ }^{*} p=0.027$; Id4, ${ }^{*} p=0.0259 ; \mathrm{Tcf}_{4},{ }^{*} p=$ 0.0238).

reduced in the NSPs differentiated in the presence of rapamycin compared with controls (supplemental Fig. 2D,E, available at www.jneurosci.org as supplemental material).

\section{Inhibiting mTOR has no effect on OPC cell number during differentiation}

To determine whether inhibiting mTOR altered cell survival, we quantified the total numbers of cells after 3.5 and $5 \mathrm{~d}$ of differentiation in the presence or absence of rapamycin. We used $\mathrm{O} 4$ as an index of cell number since all of the cells in our cultures acquired $\mathrm{O} 4$ expression by these time points. After 3.5 and $5 \mathrm{~d}$ of differentiation, we observed no change in the total number of cells in cultures treated with rapamycin versus control cultures (supplemental Fig. $3 A, B$, available at www.jneurosci.org as supplemental material).

To further evaluate cell viability, we measured changes in the level of active caspase-3 during a time course of differentiation. Inhibiting mTOR did not increase levels of active caspase- 3 at any time point (supplemental Fig. $3 C, D$, available at www.jneurosci.org as supplemental material). In fact, rapamycin treatment caused a significant reduction in the levels of active caspase- 3 after $2 \mathrm{~d}$ of differentiation (supplemental Fig. $3 D$, available at www. jneurosci.org as supplemental material $)(p=0.0375)$.

We also asked whether the differentiation block caused by inhibiting mTOR was reversible. We transiently exposed cells to rapamycin for 1-3 d, after which the culture medium was replenished with rapamycin-free media for the remainder of the experiment. On day 6 of differentiation, we quantified the number of $\mathrm{GalC}^{+}$immature oligodendrocytes by immunocytochemistry. Cultures transiently exposed to rapamycin for 1,2 , or $3 \mathrm{~d}$ showed a significant increase in the numbers of $\mathrm{GalC}^{+}$cells when compared with cells treated with rapamycin for the duration of the experiment (supplemental Fig. 3E, available at www.jneurosci.org as supplemental material $)(p<0.0001)$.

mTOR selectively regulates transcription factor activity during oligodendrocyte differentiation

The observation that mTOR regulates the expression of several myelin genes at the mRNA level suggests that mTOR regulates

the decision to commit to differentiation rather than simply affecting myelin protein levels. One possible explanation is that mTOR modulates the expression or activity of key transcription factors required for differentiation.

Transcription factors involved in oligodendrocyte specification and differentiation include but are not limited to, the basic helix-loop-helix (bHLH) family members Olig1 and Olig2, SRY box containing (Sox) family members Sox8, Sox9, Sox 10, and Sox 17, the homeobox containing (Hox) transcription factor Nkx2.2, and the zinc finger protein Yin Yang 1 (YY1). The timing of OPC differentiation is also regulated by several transcriptional inhibitors of myelin gene expression including the inhibitor of DNA binding (Id) family of proteins, Id 2 and $\operatorname{Id} 4$, and transcription factor 4 (Tcf4) (Kondo and Raff, 2000; Wang et al., 2001; Marin-Husstege et al., 2006; He et al., 2007). Therefore, we examined the effects of mTOR activation on the expression of Olig2, Sox10, Nkx2.2, Id2, Id4, and Tcf4 during oligodendrocyte differentiation in vitro. Interestingly, inhibiting mTOR did not significantly alter the mRNA levels of Olig2, Sox10, or Nkx2.2 (Fig. 4A) and there was no consistent trend suggesting an increase or decrease in these mRNAs across multiple experiments. In contrast, inhibiting mTOR increased the mRNA levels of Id2, Id4, and Tcf4 by 2.7 -fold, 3.8 -fold, and 4.6 -fold, respectively, relative to control cultures (Fig. 4 B: Id $2, p=0.027 ; \mathrm{Id} 4, p=0.0259$; Tcf4, $p=0.024)$.

\section{Two distinct mTOR signaling complexes, mTORC1 and mTORC2, are present in OPCs}

mTOR interacts directly with the adaptor proteins raptor and rictor to form two distinct signaling complexes, mTORC1 and mTORC2 respectively, that control the activation of discrete downstream signaling effectors (Kim et al., 2002; Sarbassov et al., 2004). To define the repertoire of mTOR complexes present in oligodendrocytes during differentiation, we performed coimmunoprecipitations with antibodies directed to mTOR after 1 and $2 \mathrm{~d}$ of differentiation in the presence or absence of $15 \mathrm{nM}$ rapamycin. Immune complexes were separated by SDS-PAGE followed by Western blot analysis for mTOR, raptor and rictor. Both mTORC1 and mTORC2 complexes formed during oligodendrocyte differentiation (Fig. $5 \mathrm{~A}$ ). In addition, both mTORC1 and mTORC2 dissociated in response to rapamycin treatment (Fig. 5A).

\section{mTORC1 and mTORC2 complexes exert distinct effects on OPC differentiation}

To establish whether mTORC1 and mTORC2 complexes distinctly regulate oligodendrocyte differentiation, we performed siRNA mediated knockdown of rictor and raptor. Specifically, OPCs were transiently transfected with siRNA smart pools specific for mTOR, raptor, rictor, or with a control siRNA smart pool. On day 5 of differentiation, MBP expression was quantified by Western blot analysis. We observed a marked increase in MBP expression in cells transfected with a control smart pool of siRNAs by $5 \mathrm{~d}$ of differentiation. In contrast, siRNA mediated 
knockdown of rictor or raptor decreased MBP expression by $44 \%$ and $31 \%$ respectively. (Fig. $5 B, C$ : rictor $p=0.002$, raptor $p=0.015)$.

To determine whether these complexes were affecting mRNA expression or protein translation during OPC differentiation, we measured the mRNA levels of MBP and PLP on day 3 of differentiation after transfection of siRNA smart pools targeting raptor, rictor and $\mathrm{mTOR}$. RNAi mediated silencing of $\mathrm{mTOR}$ or rictor caused a significant reduction in MBP and PLP mRNA levels (Fig. 5D: mTOR siRNA $60 \%, p=0.006$; rictor siRNA 37\%, $p=$ 0.45 , PLP not shown). Interestingly, disrupting $\mathrm{mTORC} 1$ by silencing raptor had no effect on MBP or PLP mRNA levels.

mTORC1 and $\mathrm{mTORC} 2$ regulate distinct downstream signaling targets during OPC differentiation

To gain insight into the timing of their activation during OPC differentiation, we analyzed the phosphorylation of mTOR and downstream targets. First, we evaluated the phosphorylation of mTOR on Ser 2448 during OPC differentiation (Fig. $6 A)$. We observed the sustained phosphorylation of mTOR during differentiation, which was inhibited by rapamycin (Fig. 6A).

Since Akt Ser 473 is a target of mTORC2, we analyzed phosphorylation at this site during OPC differentiation. Phosphorylation of Akt Ser 473 was sustained during OPC differentiation and was sensitive to rapamycin treatment (Fig. $6 \mathrm{~B}$ ). Therefore, we quantified the levels of Akt Ser 473 phosphorylation in the presence or absence of rapamycin treatment on days 2 and 3 of differentiation (Fig. 6C). We focused on days 2 and 3 of differentiation since: (1) Akt Ser 473 phosphorylation peaked during these time points, and (2) progression to the immature oligodendrocyte stage of differentiation coincides with 2 and $3 \mathrm{~d}$ of differentiation in vitro. We observed a $58 \%$ and $61 \%$ reduction in the level of Akt Ser 473 phosphorylation on days 2 and 3, respectively, during rapamycin treatment (day 2, $p<0.001$; day $3, p=0.002$ ) (Fig. $6 C$ ), consistent with a previous report showing that the mTORC2 complex regulates phosphorylation of Akt Ser473 (Sarbassov et al., 2005, 2006).

Next, we examined signaling targets regulated by the mTORC1 complex. Specifically, we performed Western immunoblot analyses of the phosphorylation states of p70S6K1 and 4E-BPs. We observed an acute increase in the phosphorylation of p70S6K1 Thr389 by $3 \mathrm{~h}$ of differentiation, which was maintained through $24 \mathrm{~h}$ (Fig. $6 \mathrm{D}$ ) but declined by $48 \mathrm{~h}$ (data not shown). We then examined the phosphorylation states of 4E-BPs using an antibody that recognizes both hypo- and hyper-phosphorylated forms of $4 \mathrm{E}-\mathrm{BP} 1$ and $4 \mathrm{E}-\mathrm{BP} 2$. Similar to the activation of p70S6K1, hyperphosphorylation of 4E-BP peaked within the first $24 \mathrm{~h}$ of OPC differentiation and then declined through 48 and $72 \mathrm{~h}$ (Fig. 6E). Furthermore, rapamycin inhibited the phosphorylation of p70S6K1 and 4E-BP at all time points (Fig. $6 D, E)$.
B

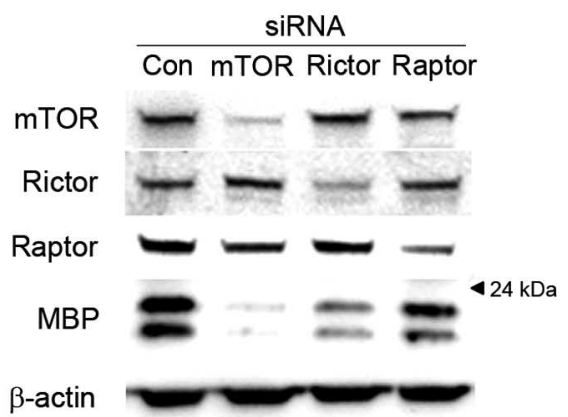

D

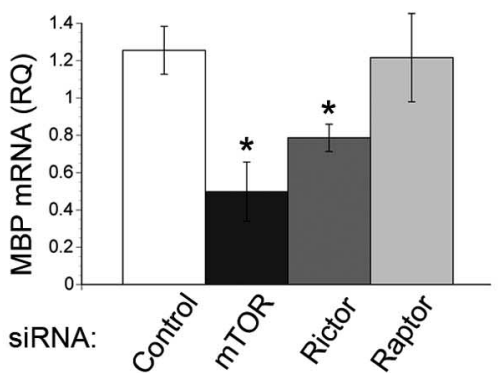

Figure 5. mTORC1 and mTORC2 complexes exert distinct effects on OPC differentiation. $\boldsymbol{A}$, Western blot analysis of mTORC1 and mTORC2 components immunoprecipitated with an antibody directed to mTOR. Samples were isolated from OPC cultures after 1 and $2 \mathrm{~d}$ of differentiation $\pm 15 \mathrm{~nm}$ rapamycin. $\boldsymbol{B}$, Western immunoblot analysis of MBP expression and mTORC1/mTORC2

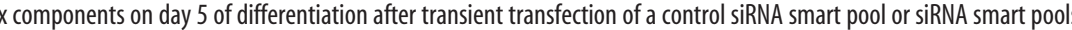
of $\mathrm{mTOR}$ or rictor caused a significant reduction in the mRNA level of MBP (mTOR siRNA 60\%, $p=0.0057$; rictor siRNA 37\%, $p=$

mTOR activation is required during the transition to the immature oligodendrocyte stage

Thus far we have shown that mTOR activity is required for OPC differentiation past the late progenitor stage. Furthermore, we showed that mTORC1 and mTORC2 complexes are formed and activate downstream signaling targets during distinct phases of oligodendrocyte differentiation. Specifically, the mTORC1 targets, p70S6K and 4E-BP, are activated early during oligodendrocyte differentiation and then decline by $48 \mathrm{~h}$, while mTORC2 mediated phosphorylation of Akt is sustained through $96 \mathrm{~h}$ of differentiation.

Because OPC differentiation in vitro takes place gradually over the course of several days, we designed an experiment to determine whether the activation of mTOR is required acutely at the onset of differentiation, or whether the activation of mTOR is required specifically during the transition to the immature oligodendrocyte stage. To define the time frame in which mTOR activation promotes OPC differentiation, we delayed the addition of rapamycin to cultures of differentiating OPCs. Specifically, rapamycin was added to OPC cultures after 1, 2, 3, and $4 \mathrm{~d}$ of differentiation. On day 5 of differentiation, the percentage of $\mathrm{GalC}^{+}$immature oligodendrocytes was quantified by immunocytochemistry and compared with untreated control cultures, or cultures that were treated with rapamycin for the entire $5 \mathrm{~d}$ period.

Consistent with previous experiments, we observed $~ 55 \%$ $\mathrm{GalC}^{+}$immature oligodendrocytes in control cultures, whereas $<1 \%$ of cells treated with rapamycin for $5 \mathrm{~d}$ were $\mathrm{GalC}^{+}$. The 
A

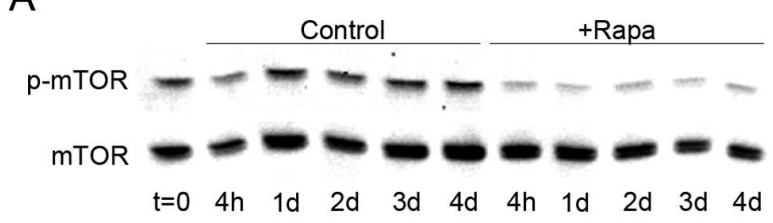

B
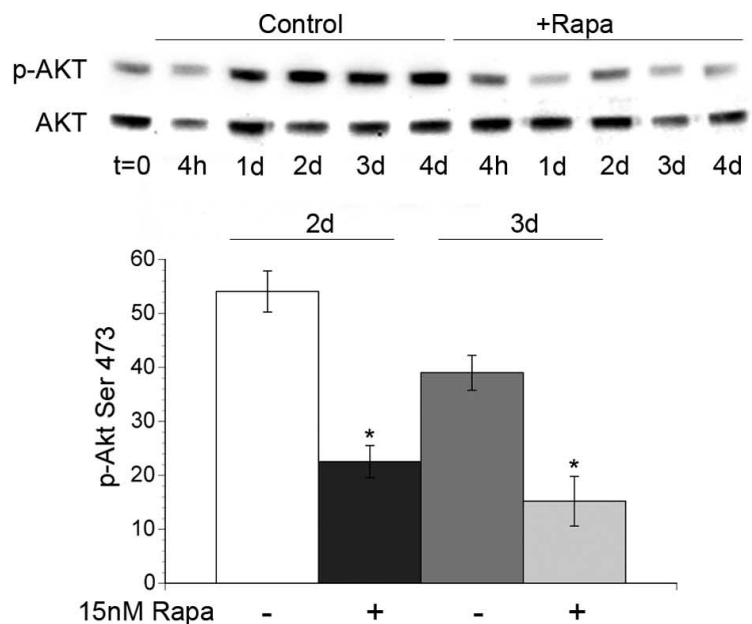

C

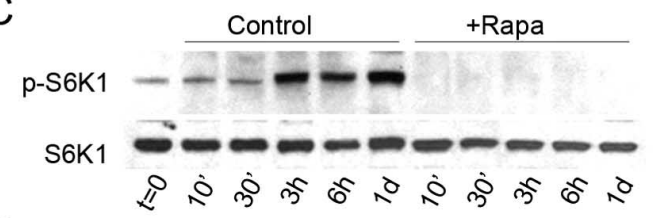

D

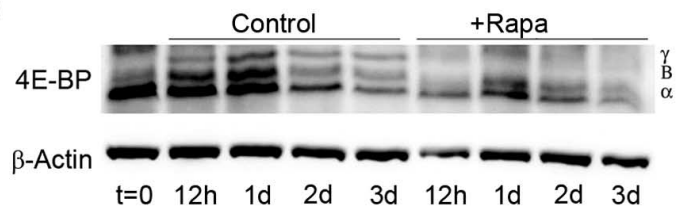

E

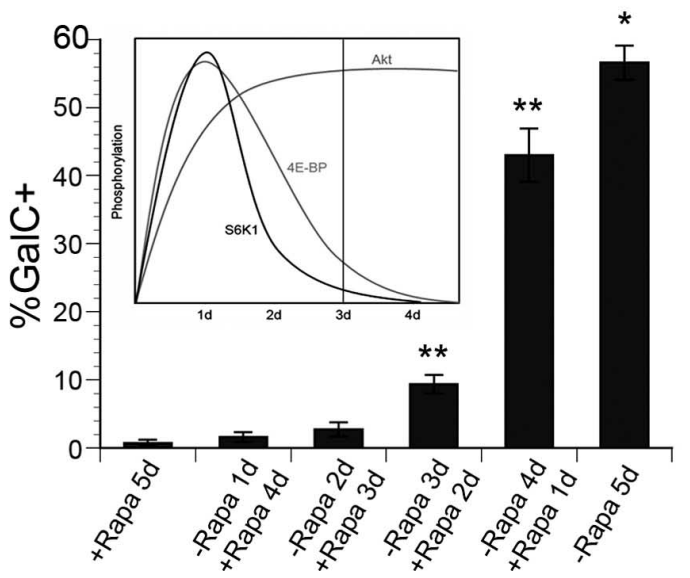

Figure 6. Activation of $m T O R C 1$ and $m$ TORC2 signaling targets during OPC differentiation. $A-C$, Western immunoblot analysis of p-mTOR Ser $2448(A)$ and p-Akt Ser $473(B)$ during OPC differentiation \pm 15 nm rapamycin. Graph (B) shows quantification of $p$-Akt Ser 473/total Akt at $2 \mathrm{~d}$ and $3 \mathrm{~d} \pm$ rapamycin. Inhibition of mTOR reduced p-Akt Ser 473 by $58 \%$ and $61 \%$ on day 2 and day 3 respectively (day $2,{ }^{*} p=0.0003 ;$ day $3,{ }^{*} p=0.0019$ ). $\boldsymbol{C}, \boldsymbol{D}$, Western immunoblot analysis of p-S6K Thr 389 (C) or 4E-BP (D) during OPC differentiation - / + rapamycin.E, mTOR activation is required during the transition to the immature oligodendrocyte stage. OPCs were cultured $-/+15 \mathrm{~nm}$ rapamycin in differentiation media for $5 \mathrm{~d}$, or rapamycin was added to cultures on days 1,2,3, and 4 after the onset of differentiation. A significant increase in $\mathrm{GalC}^{+}$ immature oligodendrocytes was observed in rapamycin treated cultures after 3 and $4 \mathrm{~d}$ of differentiation compared with cultures exposed to rapamycin for the entire $5 \mathrm{~d}\left({ }^{*} p<0.0001 \mathrm{vs}\right.$ all other conditions; ${ }^{* *} p<0.001$ vs + Rapa $5 \mathrm{~d}$ ). addition of rapamycin to cultures after 1 and $2 \mathrm{~d}$ of differentiation blocked GalC expression as efficiently as the addition of rapamycin at the onset of differentiation (Fig. $6 E$ ). In contrast, when rapamycin was added to cultures after 3 and $4 \mathrm{~d}$ in differentiation media, we observed a 13 -fold and 60 -fold increase respectively in the number of $\mathrm{GalC}^{+}$oligodendrocytes compared with cells treated with rapamycin for $5 \mathrm{~d}(p<0.0001)$ (Fig. $6 E)$.

\section{Inhibiting mTOR prevents OPC differentiation in the presence of DRG neurons}

To determine whether OPC differentiation is dependent on the activation of $\mathrm{mTOR}$ in the presence of signals derived from neurons and to test whether inhibiting mTOR would reduce myelination, we performed a series of experiments using a coculture system of OPCs seeded onto dorsal root ganglion neurons (DRGs). Rapamycin was added to OPC-DRG cultures beginning on day 2 after seeding to inhibit mTOR activation. After 7 or $18 \mathrm{~d}$ of culture in the presence or absence of rapamycin, MBP staining was performed and the number of MBP-positive oligodendrocytes as well as the number of myelin segments produced were quantified.

Inhibiting mTOR significantly reduced the number of $\mathrm{MBP}^{+}$ oligodendrocytes generated in OPC-DRG cultures after 7 or $18 \mathrm{~d}$ of differentiation for all doses of rapamycin tested (Fig. $7 A, B, E, F)$. In addition, rapamycin decreased the extent of myelination in OPC-DRG cultures on day 7 as assessed by the ratio of myelin segments to total cells (Fig. 7E). However, in longer term OPC-DRG cocultures, a decrease in the extent of myelination was only observed in cultures treated with the higher doses of rapamycin (Fig. $7 F)$.

\section{Discussion}

The current studies demonstrate that the activation of mTOR signaling is essential for differentiation of OPCs in vitro and correlates with the development of myelinating oligodendrocytes in vivo. Specifically, the activation of mTOR promotes the generation of $\mathrm{GalC}^{+}$immature oligodendrocytes in purified OPC cultures and of $\mathrm{MBP}^{+}$oligodendrocytes in the presence of DRG neurons. In contrast, the development of $\mathrm{O}^{+}{ }^{+}$late progenitors from early OPCs is independent of mTOR signaling. Thus, mTOR acts precisely during the transition to the immature oligodendrocyte stage, when OPCs commit to terminal differentiation. Our data support the hypothesis that the expression of genes required for OPC differentiation is regulated in distinct steps during lineage progression that is dependent on a combination of intrinsic and extrinsic cues. Whereas an intrinsic program may drive progression to the later progenitor stage, our data suggest that transition to the immature oligodendrocyte stage, and therefore the decision to commit to differentiation, is dependent on extrinsic factors that activate mTOR signaling.

The extrinsic signals that activate mTOR during OPC differentiation in vivo are currently unknown; however, factors that potently stimulate the PI3K/Akt pathway are likely candidates. For example, several studies have suggested that neuregulin, IGF-I, and laminin-2 promote OPC differentiation and myelination through the activation of the PI3K/Akt pathway. Of particular interest is IGF-I, which promotes OPC maturation. For example, over-expressing IGF-I in transgenic mice results in a hypermyelinated phenotype caused by increased myelin production per oligodendrocyte (Carson et al., 1993). Conversely, $\mathrm{IGF}^{-\mathrm{I}^{-\prime-}}$ mice exhibit hypomyelination characterized by a significant decrease in myelin protein expression (Ye et al., 2002). In vitro studies show that IGF-I has a profound effect on the gener- 
ation of $\mathrm{GalC}^{+}$oligodendrocytes by stimulating the differentiation of $\mathrm{O} 4+/ \mathrm{GalC}-$ late progenitors (McMorris and DuboisDelcq, 1988). Furthermore, the media used to initiate differentiation contain micromolar levels of insulin, known to stimulate the IGF-IR, and as such can be considered IGF-I supplemented. In addition, a recent report by Swamydas et al. (2008) showed that the neuroactive steroids, progesterone and estrogen, potently activate Akt/mTOR signaling in enriched cultures of oligodendrocytes.

Our studies implicate Akt/mTOR signaling as a critical pathway for the generation of mature oligodendrocytes. Interestingly, recent studies demonstrated that activation of the p38 MAPK pathway promotes oligodendrocyte differentiation (Bhat et al., 2007; Fragoso et al., 2007). Future studies are required to determine whether cross talk occurs between the p38 MAPK and Akt/mTOR pathways or whether they act in a parallel manner to promote OPC differentiation.

Our data demonstrate that mTOR regulates the expression of several key transcriptional repressors during OPC differentiation. Specifically, mTOR signaling decreases the expression of Id2, Id4, and Tcf4. Previous studies show that ectopic expression of each of these transcriptional repressors is sufficient to arrest OPC differentiation at the late progenitor stage, effectively blocking the emergence of $\mathrm{GalC}^{+}$ immature oligodendrocytes (Kondo and Raff, 2000; Wang et al., 2001; He et al., 2007). These data suggest that a primary function of mTOR activation during OPC differentiation is to suppress the expression of transcriptional repressors, relieving their inhibition on oligodendrocyte maturation. Because of the transcriptional control exerted by Id2, Id4, and Tcf4, we hypothesize that these factors are targets of the mTORC2 complex. Interestingly, a link between mTOR and Id 4 and Tcf 4 may be explained by the ability of mTOR to form a complex with and modulate the activity of the transcription factor YY1, which has previously been shown to regulate the expression of Id4 and Tcf4 during oligodendrocyte differentiation (Cunningham et al., 2007; He et al., 2007).

Our data show that signaling through both mTORC1 and mTORC2 is required during OPC differentiation, supporting the conclusion that each complex contributes to the generation of mature oligodendrocytes through distinct mechanisms. Disrupting $\mathrm{mTORC} 1$ or $\mathrm{mTORC} 2$ reduces the protein levels of MBP during differentiation. However, only mTORC2 regulates the expression of the myelin genes MBP and PLP at the mRNA level. These data suggest that mTORC2 transcriptionally controls key genes required for OPC differentiation, whereas mTORC1 influences the generation of mature oligodendrocytes through an alternate mechanism. Since mTORC1 targets, particularly 4E-BP, mediate translation of specific mRNAs, it is likely that mTORC1 regulates the translation of myelin genes.

The observation that mTORC1 and mTORC2 phosphorylate distinct downstream signaling effectors in a temporal manner provides additional support for the hypothesis that each complex exerts a unique role during OPC differentiation. Specifically, the mTORC1 targets, p70S6K1 and 4E-BP, were phosphorylated acutely during the onset of differentiation. However, the phosphorylation of these targets declined by $48 \mathrm{~h}$. In contrast, the phosphorylation of Akt Ser473, a substrate of the mTORC2 complex, increased significantly by $24 \mathrm{~h}$ of differentiation and was sustained through $96 \mathrm{~h}$. Inhibiting mTOR completely abrogated the phosphorylation of mTORC1 targets and partially, yet significantly, decreased the phosphorylation of Akt Ser473, representing an mTORC2-sensitive pool of Akt.

Our data suggest that the activation of mTORC1 targets, while necessary, are not sufficient to promote OPC differentiation. The delayed addition of rapamycin to cultures of differentiating OPCs showed that the addition of rapamycin after $2 \mathrm{~d}$ of differentiation, subsequent to the peak activation of the mTORC1 targets examined, was as effective at blocking the generation of $\mathrm{GalC}^{+}$postmitotic oligodendrocytes as the addition of rapamycin at the onset of differentiation. Alternatively, additional targets of the mTORC1 complex may exert their effects during OPC differentiation. Furthermore, the sustained activation of Akt, caused in part by signaling via 
mTORC2, correlates directly with the transition to the immature oligodendrocyte stage.

Recent studies of transgenic mice that express a constitutively active Akt (Akt-DD) in the oligodendrocyte lineage support a role for mTOR signaling in OPC differentiation and myelination (Flores et al., 2008). Specifically, PLP-Akt-DD mice exhibit an increase in the generation of premyelinating oligodendrocytes by postnatal day 14 and subsequent hypermyelination that persists in adult mice. In addition, recent studies by the Macklin laboratory show a significant increase in the levels of phosphorylated mTOR and p70S6K on postnatal day 21 and in actively myelinating adult oligodendrocytes in PLP-Akt-DD brains (Narayanan et al., 2009). The administration of rapamycin to 6-week-old PLPAkt-DD mice inhibited the effect of active Akt on myelination. Furthermore, postnatal day 21 old WT mice treated with rapamycin exhibited a reduction in the PLP, MBP, CNP and MOG protein and mRNA expression and decreased myelination. These data are consistent with the hypothesis that the enhanced stimulation of mTOR leads to the precocious development of myelinating oligodendrocytes in vivo, and that mTOR signaling is essential for normal myelination (Narayanan et al., 2009).

A central question in the development of myelinating oligodendrocytes is whether the differentiation of OPCs and myelination are regulated by unique mechanisms (for review, see Rosenberg et al., 2007). Elegant studies of postnatal development in the optic nerve demonstrate that the sequence of OPC differentiation and myelination is temporally and spatially distinct, suggesting that different signals are required to direct each process (Colello et al., 1995). In addition, microarray studies suggest that the terminal differentiation of oligodendrocytes occurs in a series of sequential steps that includes at least two phases of myelin gene induction regulated by independent sets of transcription factors (Dugas et al., 2006). In OPC-DRG cocultures, inhibiting mTOR blocked the appearance of $\mathrm{MBP}^{+}$oligodendrocytes, similar to the effect seen in isolated OPC cultures. In contrast, the inhibition of mTOR at lower doses of rapamycin had a less pronounced effect on myelination. These data support the idea that myelination is governed by a process distinct from that which regulates differentiation. However, the possibility exists that low doses of rapamycin were not sufficient to completely block activation of mTOR, as a significant effect on myelination was observed for cocultures treated with a high dose of rapamycin. In conclusion, these data support a clear role for the activation of mTOR during a critical stage of OPC differentiation, whereas a subsequent role for $\mathrm{mTOR}$ in regulating the process of myelination during development is less clear. On the other hand, the higher dose of rapamycin did effect myelination in agreement with data showing that overexpression of Akt/mTOR induces hypermyelination (Narayanan et al., 2009).

The data presented here provide strong evidence to suggest that mTOR signaling is a novel pathway required for OPC differentiation. Most functional studies on the PI3K/Akt/mTOR pathway have focused on its role in cell size and cell proliferation. However, mTOR signaling has been implicated in the timing of neuronal differentiation in the Drosophila eye and has been reported to promote mammalian neurogenesis in response to insulin/IGF-I mediated activation of the PI3K/Akt pathway (Bateman and McNeill, 2004; Han et al., 2008). In our studies, the mTOR pathway appears to selectively promote differentiation of oligodendrocytes but not astrocytes or neurons. Accordingly, signaling via mTOR represents an intriguing target for therapeutic intervention to promote remyelination in disorders such as multiple sclerosis.

\section{References}

Bateman JM, McNeill H (2004) Temporal control of differentiation by the insulin receptor/tor pathway in Drosophila. Cell 119:87-96.

Beck KD, Powell-Braxton L, Widmer HR, Valverde J, Hefti F (1995) Igf1 gene disruption results in reduced brain size, CNS hypomyelination, and loss of hippocampal granule and striatal parvalbumin-containing neurons. Neuron 14:717-730.

Bhat NR, Zhang P, Mohanty SB (2007) p38 MAP kinase regulation of oligodendrocyte differentiation with CREB as a potential target. Neurochem Res 32:293-302.

Carson MJ, Behringer RR, Brinster RL, McMorris FA (1993) Insulin-like growth factor I increases brain growth and central nervous system myelination in transgenic mice. Neuron 10:729-740.

Choe G, Horvath S, Cloughesy TF, Crosby K, Seligson D, Palotie A, Inge L, Smith BL, Sawyers CL, Mischel PS (2003) Analysis of the phosphatidylinositol 3'-kinase signaling pathway in glioblastoma patients in vivo. Cancer Res 63:2742-2746.

Chun SJ, Rasband MN, Sidman RL, Habib AA, Vartanian T (2003) Integrinlinked kinase is required for laminin-2-induced oligodendrocyte cell spreading and CNS myelination. J Cell Biol 163:397-408.

Colello RJ, Devey LR, Imperato E, Pott U (1995) The chronology of oligodendrocyte differentiation in the rat optic nerve: evidence for a signaling step initiating myelination in the CNS. J Neurosci 15:7665-7672.

Cunningham JT, Rodgers JT, Arlow DH, Vazquez F, Mootha VK, Puigserver $\mathrm{P}$ (2007) mTOR controls mitochondrial oxidative function through a YY1-PGC-1alpha transcriptional complex. Nature 450:736-740.

Dugas JC, Tai YC, Speed TP, Ngai J, Barres BA (2006) Functional genomic analysis of oligodendrocyte differentiation. J Neurosci 26:10967-10983.

Felling RJ, Snyder MJ, Romanko MJ, Rothstein RP, Ziegler AN, Yang Z, Givogri MI, Bongarzone ER, Levison SW (2006) Neural stem/progenitor cells participate in the regenerative response to perinatal hypoxia/ ischemia. J Neurosci 26:4359-4369.

Flores AI, Narayanan SP, Morse EN, Shick HE, Yin X, Kidd G, Avila RL, Kirschner DA, Macklin WB (2008) Constitutively active Akt induces enhanced myelination in the CNS. J Neurosci 28:7174-7183.

Fragoso G, Haines JD, Roberston J, Pedraza L, Mushynski WE, Almazan G (2007) p38 mitogen-activated protein kinase is required for central nervous system myelination. Glia 55:1531-1541.

Hamano K, Iwasaki N, Takeya T, Takita H (1996) A quantitative analysis of rat central nervous system myelination using the immunohistochemical method for MBP. Brain Res Dev Brain Res 93:18-22.

Han J, Wang B, Xiao Z, Gao Y, Zhao Y, Zhang J, Chen B, Wang X, Dai J (2008) Mammalian target of rapamycin (mTOR) is involved in the neuronal differentiation of neural progenitors induced by insulin. Mol Cell Neurosci 39:118-124.

Hay N, Sonenberg N (2004) Upstream and downstream of mTOR. Genes Dev 18:1926-1945.

He Y, Dupree J, Wang J, Sandoval J, Li J, Liu H, Shi Y, Nave KA, CasacciaBonnefil P (2007) The transcription factor Yin Yang 1 is essential for oligodendrocyte progenitor differentiation. Neuron 55:217-230.

Holz MK, Blenis J (2005) Identification of S6 kinase 1 as a novel mammalian target of rapamycin (mTOR)-phosphorylating kinase. J Biol Chem 280:26089-26093.

Hu X, Hicks CW, He W, Wong P, Macklin WB, Trapp BD, Yan R (2006) Bace1 modulates myelination in the central and peripheral nervous system. Nat Neurosci 9:1520-1525.

Kim DH, Sarbassov DD, Ali SM, King JE, Latek RR, Erdjument-Bromage H, Tempst P, Sabatini DM (2002) mTOR interacts with raptor to form a nutrient-sensitive complex that signals to the cell growth machinery. Cell 110:163-175.

Kondo T, Raff M (2000) The Id4 HLH protein and the timing of oligodendrocyte differentiation. EMBO J 19:1998-2007.

Koul O, Chou KH, Jungalwala FB (1980) UDP-galactose-ceramide galactosyltransferase in rat brain myelin subfractions during development. Biochem J 186:959-969.

Marin-Husstege M, He Y, Li J, Kondo T, Sablitzky F, Casaccia-Bonnefil P (2006) Multiple roles of Id4 in developmental myelination: predicted outcomes and unexpected findings. Glia 54:285-296.

McCarthy KD, de Vellis J (1980) Preparation of separate astroglial and oligodendroglial cell cultures from rat cerebral tissue. J Cell Biol 85:890-902. McMorris FA, Dubois-Dalcq M (1988) Insulin-like growth factor I pro- 
motes cell proliferation and oligodendroglia commitment in rat glial progenitor cells developing in vitro. J Neurosci Res 21:199-209.

Narayanan SP, Flores AI, Wang F, Macklin WB (2009) Akt signals through the mammalian target of rapamycin, mTOR, pathway to regulate central nervous system myelination. J Neurosci, in press.

Ness JK, Wood TL (2002) Insulin-like growth factor I, but not neurotrophin-3, sustains Akt activation and provides long-term protection of immature oligodendrocytes from glutamate-mediated apoptosis. Mol Cell Neurosci 20:476-488.

Rosenberg SS, Powell BL, Chan JR (2007) Receiving mixed signals: uncoupling oligodendrocyte differentiation and myelination. Cell Mol Life Sci 64:3059-3068.

Sarbassov DD, Ali SM, Kim DH, Guertin DA, Latek RR, Erdjument-Bromage H, Tempst P, Sabatini DM (2004) Rictor, a novel binding partner of mTOR, defines a rapamycin-insensitive and raptor-independent pathway that regulates the cytoskeleton. Curr Biol 14:1296-1302.

Sarbassov DD, Guertin DA, Ali SM, Sabatini DM (2005) Phosphorylation and regulation of Akt/PKB by the rictor-mTOR complex. Science 307:1098-1101.

Sarbassov DD, Ali SM, Sengupta S, Sheen JH, Hsu PP, Bagley AF, Markhard AL, Sabatini DM (2006) Prolonged rapamycin treatment inhibits mTORC2 assembly and Akt/PKB. Mol Cell 22:159-168.
Sekulić A, Hudson CC, Homme JL, Yin P, Otterness DM, Karnitz LM, Abraham RT (2000) A direct linkage between the phosphoinositide 3-kinaseAKT signaling pathway and the mammalian target of rapamycin in mitogen-stimulated and transformed cells. Cancer Res 60:3504-3513.

Swamydas M, Bessert D, Skoff R (2008) Sexual dimorphism of oligodendrocytes is mediated by differential regulation of signaling pathways. J Neurosci Res. Advance online publication. Retrieved April 30, 2009. doi:10.1002/jnr.21943.

Tokumoto YM, Durand B, Raff MC (1999) An analysis of the early events when oligodendrocyte precursor cells are triggered to differentiate by thyroid hormone, retinoic acid, or PDGF withdrawal. Dev Biol 213:327-339.

Wang S, Sdrulla A, Johnson JE, Yokota Y, Barres BA (2001) A role for the helix-loop-helix protein Id2 in the control of oligodendrocyte development. Neuron 29:603-614.

Ye P, Li L, Richards RG, DiAugustine RP, D’Ercole AJ (2002) Myelination is altered in insulin-like growth factor-I null mutant mice. J Neurosci 22:6041-6051.

Zeger M, Popken G, Zhang J, Xuan S, Lu QR, Schwab MH, Nave KA, Rowitch D, D’Ercole AJ, Ye P (2007) Insulin-like growth factor type 1 receptor signaling in the cells of oligodendrocyte lineage is required for normal in vivo oligodendrocyte development and myelination. Glia 55:400-411. 